\title{
Study of corrosion of combinations of titanium/Ti-6Al-4V implants and dental alloys
}

\author{
Masatoshi YAMAZOE \\ Division of Biomaterials, Department of Hard Tissue Research, Graduate School of Oral Medicine, Matsumoto Dental University, 1780 Gobara \\ Hirooka Shiojiri, Nagano 399-0781, Japan \\ Corresponding author, Masatoshi YAMAZOE; E-mail: yamazoe@yamakin-gold.co.jp
}

\begin{abstract}
Metal ions released in 1\% lactic acid solution from combinations of titanium fixtures with superstructures made of dental precious metal alloys (dental alloys) and titanium and differences based on the fixing method were investigated. In combinations of titanium with dental alloys, the level of Ti release was influenced by micro-structure of titanium: it was lower when the grain size was smaller. In titanium-titanium combinations, differences in the micro-structure of metal also markedly influenced the dissolution: the level of release increased when the micro-structure of titanium was different. The Ti and $\mathrm{V}$ release levels were higher in combination with titanium alloy and titanium than with titanium alloy and dental alloys. Regarding the superstructure-fixture fixing method, the level of Ti release was significantly lower in cement than in direct fixation.
\end{abstract}

Keywords: Implant, Dissolution of metal ions, Micro-structure of titanium

\section{INTRODUCTION}

Fixture-implanting treatment has recently been increasingly applied, and cement fixation is frequently employed to bind fixtures with superstructures because of its superiority to screw fixation regarding the esthetic appearance, fit accuracy, and procedure ${ }^{1-5)}$. Because titanium and dental gold alloys are not in direct contact due to the cement, which it is an insulator, cement fixation of superstructures to fixtures does not produce a galvanic current and is less likely to cause corrosion. However, there has been no study on metal ion release due to differences in the fixation method.

Dental implants are comprised of several structures depending on the procedure and cases, such as fixtures, abutments, and fixation screws, and not only titanium but also titanium alloy is used for the composition. In addition, micro-structure of metal of some fixtures varies depending on the diameter ${ }^{6}$, but its influence on metal ion release has not been investigated.

The important point on the in vitro evaluation of the corrosion resistance of dental metals is reproduction of the oral environment, for which selection of the test solution is significant. Solutions simulating the biological conditions include $0.9 \% \mathrm{NaCl}$ solution, phosphate-buffered saline (PBS (-)), and artificial saliva $^{7-10)}$. Yoneyama et al. ${ }^{11)}$ pointed out that $0.9 \%$ $\mathrm{NaCl}$ solution reproduced the body fluid to some extent, but lacked quantitative properties, particularly, reliability of the released $\mathrm{Ti}$ ion level, and 1.0\% lactic acid solution was suitable. Okazaki et al. ${ }^{12)}$ placed titanium alloy implants in the rat tibia, and observed that the metal level in tissue near the implant placement site was higher than the levels in calf serum and released in PBS (-) but lower than that released in
$1.0 \%$ lactic acid solution, based on which they recommended $1.0 \%$ lactic acid solution as a suitable as well as simple solution for accelerated immersion testing. Accordingly, I adopted 1.0\% lactic acid solution. On the other hand, natural electrode potentials generated between different metals, the potentiodynamic polarization curve, and changes in the galvanic current potential and density were reported in detail as electrochemical properties with regard to the evaluation of the corrosion resistance of biological metal materials ${ }^{13-18)}$. However, it is difficult to electrochemically reproduce clinically important conditions in the presence of influences of luting agents and adhesives used for fixation and between-space corrosion and the tightening stress of screw fixation.

In this study, I performed immersion tests of 5 types of combination of superstructures prepared with dental precious metal alloys (dental alloys), titanium, titanium alloy, and acryl with titanium, titanium alloy, and acryl as control fixtures in lactic acid solution, in order to investigate the following 4 items: 1 ) influences of fixation methods to bind fixtures with superstructures (direct and cement fixations); 2) influences of titanium fixture/superstructure combinations; 3) influences of the micro-structure of titanium fixture; and 4) influences of combination with the titanium alloy fixture. The levels of metal ion release and discoloration after emersion were measured, and the micro-structure of metal and surface were observed. These were also compared between the combinations bound by cement and direct fixations.

\section{MATERIALS AND METHODS}

Preparation of test samples

Experiments were performed using metal materials (3 types of titanium with different degrees of processing, 
titanium alloy, 5 types of porcelain-fused-to-metal (PFM) alloy, 5 types of gold alloy, silver-palladiumcopper-gold alloy, and silver alloy, presented with codes below) shown in Table 1, and acryl as a control, and 4 types of superstructure: those prepared with dental alloys cast by the lost wax method, lathed titanium and titanium alloy, and acryl. The diameter and length of superstructures were 6 and $4.8 \mathrm{~mm}$, respectively. Fixtures were cut out from wires with a diameter and length of 4 and $17 \mathrm{~mm}$, respectively, and the tip was 6degree tapered over a 3.8-mm length (Fig. 1). The titanium superstructure, STi, and titanium fixture, FTi, were prepared with wire of 6- and 4-mm in diameter, Ti1 and Ti2, respectively (Table 1). The titanium superstructure, STi2, and titanium fixture, FTi2, were prepared with wire of $6-\mathrm{mm}$ in diameter (Ti3) (Table 1). The titanium alloy (Ti-6Al-4V) superstructure, S64, and titanium alloy (Ti-6Al-4V) fixture, F64, were prepared with wire of $8.5-\mathrm{mm}$ in diameter, Ti64 (Table 1). These were lathed using oil, and their surface roughnesses $(R \mathrm{a}: \mu \mathrm{m})$ were FTi: 1.03 , FTi2: 0.95, F64: 0.96, STi: 0.54, STi2: 0.57, and S64: 0.58. Dental alloys were cast into investment molds using a vacuum pressure casting machine (CASPAC 8000, Dentronics Co., Tokyo, Japan) according to manufacturer's instructions. Casted dental alloys were finally polished with Deerskin Buff (MOMOSE DENTAL MFG. Co., Osaka, Japan) and a polishing material, Multi Blue (DAIEI DENTAL PRODUCT Co., Osaka, Japan). Acryl used for the comparative control acrylic fixtures (FAc) was cut from wire of $4-\mathrm{mm}$ in diameter, and that used for the acrylic superstructure
(SAc) was prepared by mechanically combining a pipe with outer and inner diameters of 6 and $4 \mathrm{~mm}$, respectively, and 4-mm wire. Ti was ultrasonicated in acetone and distilled water, dental alloys in ethanol and distilled water, and acryl in distilled water. Superstructures and fixtures were bound employing 2 fixing methods: direct and cement fixations, and 5 combinations of the superstructure-fixture combinations

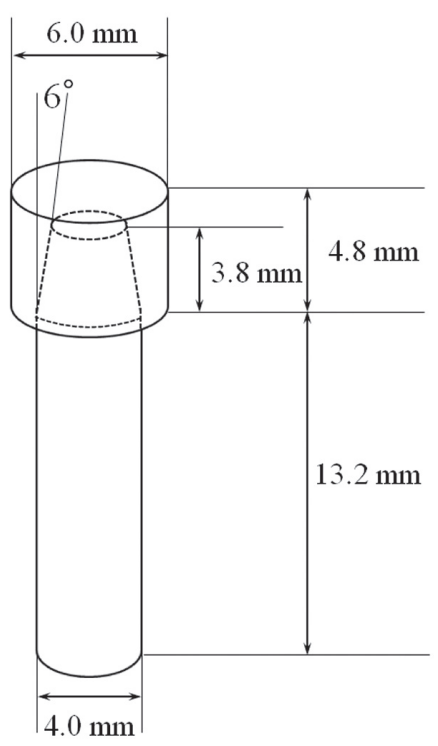

Fig. 1 Schematic diagram of test sample (superstructure and fixture).

Table 1 Metal materials used in experiments and their codes

\begin{tabular}{|c|c|c|c|c|}
\hline Materials & Code ${ }^{* 1}$ & Trade name & Manufacturer & Composition $(\operatorname{mass} \%)^{* 2}$ \\
\hline \multirow{3}{*}{ Titanium } & Ti1 & TITANIUM WIRE & Suzuki Metal Industry & 99.839Ti-0.001H-0.1O-0.01N-0.05Fe \\
\hline & Ti2 & TITANIUM WIRE & Nabekura Metal Industry & 99.8342Ti-0.0028H-0.09O-0.003N-0.06Fe-0.01C \\
\hline & $\mathrm{Ti} 3$ & TITANIUM WIRE & Nabekura Metal Industry & 99.8343Ti-0.0017H-0.09O-0.004N-0.06Fe-0.01C \\
\hline \multirow[t]{3}{*}{ Titanium Alloy } & Ti64 & TITANIUM ALLOY WIRE & Daido Steel & 89.477Ti-6.21Al-4V-0.003H-0.150-0.01N-0.14Fe-0.01C \\
\hline & $\mathrm{C} 98$ & ZEO METAL 87 & Yamamoto Precious Metal & $87 \mathrm{Au}-11 \mathrm{Pt}-2(\mathrm{Zn}, \mathrm{Ir})$ \\
\hline & $\mathrm{C} 94$ & SUPER CRYSTAL KP-5 & Yamamoto Precious Metal & 75Au-6.7Pt-12.3Pd-1.8Ag-4.2(In, Sn, Re, Ir, Ga, Fe, Cu) \\
\hline \multirow[t]{5}{*}{ PFM Alloy*3 } & $\mathrm{C} 83$ & QUINTESS CERAFY & Yamamoto Precious Metal & $56 \mathrm{Au}-2 \mathrm{Pt}-24.5 \mathrm{Pd}-13 \mathrm{Ag}-4.5(\mathrm{In}, \mathrm{Sn}, \mathrm{Ru})$ \\
\hline & $\mathrm{C} 82$ & ZEO METAL 53 & Yamamoto Precious Metal & $53 \mathrm{Au}-1.5 \mathrm{Pt}-27.5 \mathrm{Pd}-12.3 \mathrm{Ag}-5.7(\mathrm{Sn}, \mathrm{In}, \mathrm{Ir}, \mathrm{Cu}, \mathrm{Ga})$ \\
\hline & C61 & ZEO METAL ST & Yamamoto Precious Metal & 60.5Pd-27Ag-5.7Sn-5.4In-1.4(Zn, Ga , Ru \\
\hline & G77 & BENEFIT G & Yamamoto Precious Metal & 70Au-4.5Pt-2Pd-13.6Ag-8.8Cu-1.1(Zn, Ir) \\
\hline & G76 & YP GOLD TYPE IV & Yamamoto Precious Metal & $71 \mathrm{Au}-2 \mathrm{Pt}-3 \mathrm{Pd}-8 \mathrm{Ag}-15 \mathrm{Cu}-(\mathrm{Zn}, \mathrm{Ir})$ \\
\hline \multirow[t]{3}{*}{ Gold Alloy } & G75A & B.I YELLOW & Yamamoto Precious Metal & 71Au-4Pt-12.3Ag-12.1Cu-0.6(Zn, Ir) \\
\hline & G75B & BENEFIT JUSTY & Yamamoto Precious Metal & $68 \mathrm{Au}-7 \mathrm{Pt}-16.2 \mathrm{Ag}-8 \mathrm{Cu}-0.8(\mathrm{Zn}, \mathrm{Ir})$ \\
\hline & G58 & SPACY J & Yamamoto Precious Metal & $50 \mathrm{Au}-4.5 \mathrm{Pt}-3.2 \mathrm{Pd}-32.7 \mathrm{Ag}-9 \mathrm{Cu}-(\mathrm{Zn}, \mathrm{Ir})$ \\
\hline $\begin{array}{l}\text { Ag-Pd-Cu-Au } \\
\text { Alloy }\end{array}$ & GP & PALLA Z 12 & Yamamoto Precious Metal & $12 \mathrm{Au}-20 \mathrm{Pd}-50 \mathrm{Ag}-16.5 \mathrm{Cu}-1.5(\mathrm{Zn}, \mathrm{In}, \mathrm{Ga}, \mathrm{Ir})$ \\
\hline Silver Alloy & SL & UNICOM-7 & Yamamoto Precious Metal & 0.7Pd-70Ag-20.5In-6.2Zn-2.6(Sn, Ir, Al) \\
\hline
\end{tabular}


Table 2 Materials used for fixtures and superstructure and fixation methods

\begin{tabular}{lcccc}
\hline & DB-FTi & CB-FTi & CB-FAc & DB-FTi2 \\
\hline Fixture & FTi & FTi & FAc & FTi2
\end{tabular}

with these 2 fixing methods were tested (Table 2).

FTi and superstructures prepared with 13 metals (STi, C98, C94, C83, C82, C61, G77, G76, G75A, G75B, G58, GP, and SL) bound by direct fixation were designated as DB-FTi and those by cement fixation as CB-FTi. As controls not combined with titanium, FAc and superstructures bound by cement fixation were designated as CB-FAc. FTi2 and superstructures prepared with 5 metals (STi2, C94, G76, GP, and SL) bound by direct fixation were designated as DB-FTi2, and the titanium alloy fixture F64 and superstructures prepared with 6 metals (S64, C94, G76, GP, SL, and STi) bound by direct fixation as DB-F64. Direct fixation was applied on the assumption of screw fixation, in which a 30-kg weight was loaded for 5 minutes for fitting using a constant-load tester (Nihon Mecu Co., Tokyo, Japan). In cement fixation, fixtures and superstructures were bound using adhesive glass ionomer resin cement (GC Fuji Luting S, GC Co., Tokyo, Japan) followed by loading a 5-kg weight using a constant-load tester. Excess cement was removed during the 5-minute loading. The test samples bound by cement fixation were kept in $37^{\circ} \mathrm{C}$ distilled water for 24 hours after weight loading. Seven test samples were prepared for each condition.

\section{Immersion test}

The test sample was immersed in $50 \mathrm{~mL}$ of $1 \%$ lactic acid solution and shaken 50 times/min for 3 months in a $37^{\circ} \mathrm{C}$ shaking incubator (IK400W, Yamato Scientific Co., Tokyo, Japan). The samples bound by direct fixation were immersed immediately after binding and those bound by cement fixation were immersed after keeping them in $37^{\circ} \mathrm{C}$ distilled water for 24 hours.

\section{Quantification of metal ion release}

After immersion, the test samples were taken out, metal ions that had been released into $1 \%$ lactic acid solution were measured 3 times using an Inductively Coupled Plasma-Atomic Emission Spectrometry (ICPE9000, Shimadzu Co., Kyoto, Japan), and the mean was calculated employing the 3-point calibration method. In addition, the levels of $\mathrm{Ti}$ and $\mathrm{V}$ ion release per unit area were also determined. Metal ion measurement was limited to metals contained in the samples.

\section{Measurement of color differences between before and} after immersion

To measure color differences between before and after immersion, the reflectance at $300-800-\mathrm{nm}$ wavelengths including regular reflection was measured at the occlusal surface of the superstructure 20 times before and after immersion in each test sample using a spectrophotometer (PMA-10, Hamamatsu Photonics K. K., Shizuoka, Japan), and the color difference $\left(\Delta E^{*} a b\right)$ was calculated from the means.

\section{Observation of micro-structure of metal}

Titanium and titanium alloy (STi, STi2, S64, FTi, FTi2, and F64) were embedded with acryl resin, polished to a mirror state using an automatic polisher (AUTOMETO 2/ECOMET 3, BUEHLER, Illinois, USA), and etched using chemical polishing solution for titanium (CHEMIPOLISH, SHOFU, Kyoto, Japan), followed by observation under a scanning confocal laser microscope (LEXT OLS3000, Olympus Co., Tokyo, Japan).

\section{Surface observation}

The test sample surfaces were observed under the scanning confocal laser microscope before and after immersion.

\section{Statistical analysis}

Bartlett's test was employed for tests classified by a single factor. One-way ANOVA was used when the distribution was homogenous, and the Kruskal-Wallis test was employed when the distribution was not homogenous. For tests classified by 2 factors, the Levene test was employed, two-way ANOVA was used when the distribution was homogenous, and Bonferroni's multiple comparison was applied when the distribution was not homogenous.

\section{RESULTS}

Quantification of metal ion release

Table 3 shows metal ion release from DB-FTi, CB-FTi, and CB-FAc. Seven ion metals: Ag, Cu, Ga, In, Sn, Zn, and $\mathrm{Ti}$, were released. The highest total level of metal ion release was noted in the combinations with SL regardless of the condition, followed by gold alloys and GP, whereas releases from combinations with PFM alloys and titanium were low-level. Of trace elements contained in PFM alloys, non-precious metals, such as 
Table 3 Total levels of metal ion release from DB-FTi, CB-FTi, and CB-FAc

\begin{tabular}{|c|c|c|c|c|c|c|c|c|c|}
\hline \multicolumn{2}{|c|}{ Sample } & \multirow[b]{2}{*}{$\mathrm{Ag}$} & \multirow[b]{2}{*}{$\mathrm{Cu}$} & \multicolumn{3}{|c|}{ Released ion concentration (ppm) } & \multirow[b]{2}{*}{$\mathrm{Ti}$} & \multirow[b]{2}{*}{$\mathrm{Zn}$} & \multirow[b]{2}{*}{ Total } \\
\hline $\begin{array}{c}\text { Super- } \\
\text { structure }\end{array}$ & Group & & & $\mathrm{Ga}$ & In & $\mathrm{Sn}$ & & & \\
\hline \multirow{3}{*}{ STI } & DB-FTi & - & - & - & - & - & $1.419 \quad(0.599)$ & - & 1.419 \\
\hline & CB-FTi & - & - & - & - & - & $0.1683(0.034)$ & - & 0.168 \\
\hline & CB-FAc & - & - & - & - & - & $0.1156(0.016)$ & - & 0.116 \\
\hline \multirow{3}{*}{ C98 } & DB-FTi & - & - & - & - & - & $0.246 \quad(0.068)$ & $11.495 \quad(4.701)$ & 11.741 \\
\hline & CB-FTi & - & - & - & - & - & $0.1046(0.046)$ & $11.079(10.320)$ & 11.183 \\
\hline & CB-FAc & - & - & - & - & - & $0.0203(0.002)$ & $3.062(1.750)$ & 3.082 \\
\hline \multirow{3}{*}{ C94 } & DB-FTi & - & - & $0.125(0.065)$ & $1.111(0.183)$ & $0.058(0.013)$ & $0.254 \quad(0.081)$ & - & 1.548 \\
\hline & CB-FTi & Traces & - & $0.295(0.132)$ & $1.293(0.142)$ & $0.080(0.006)$ & $0.0759(0.007)$ & - & 1.744 \\
\hline & CB-FAc & Traces & - & $0.122(0.044)$ & $0.544(0.103)$ & Traces & $0.0160(0.002)$ & - & 0.682 \\
\hline \multirow{3}{*}{$\mathrm{C} 83$} & DB-FTi & Traces & - & - & $0.710(0.270)$ & $0.066(0.024)$ & $0.235 \quad(0.081)$ & - & 1.011 \\
\hline & CB-FTi & Traces & - & - & $0.304(0.061)$ & Traces & $0.0581(0.022)$ & - & 0.362 \\
\hline & CB-FAc & Traces & - & - & $0.132(0.043)$ & - & $0.0216(0.005)$ & - & 0.154 \\
\hline \multirow{3}{*}{$\mathrm{C} 82$} & DB-FTi & Traces & - & $0.124(0.016)$ & $0.849(0.262)$ & $0.060(0.022)$ & $0.272 \quad(0.060)$ & - & 1.305 \\
\hline & CB-FTi & Traces & - & $0.048(0.012)$ & $0.467(0.067)$ & Traces & $0.0747(0.010)$ & - & 0.590 \\
\hline & CB-FAc & Traces & - & $0.043(0.011)$ & $0.216(0.035)$ & - & $0.0173(0.003)$ & - & 0.276 \\
\hline \multirow{3}{*}{ C61 } & DB-FTi & $0.019(0.007)$ & - & $0.083(0.053)$ & $0.309(0.084)$ & Traces & $0.186 \quad(0.062)$ & - & 0.597 \\
\hline & CB-FTi & $0.256(0.396)$ & - & $0.071(0.069)$ & $0.437(0.279)$ & $0.058(0.042)$ & $0.0756(0.011)$ & Traces & 0.897 \\
\hline & CB-FAc & $0.031(0.004)$ & - & $0.036(0.008)$ & $0.196(0.037)$ & Traces & $0.0182(0.004)$ & - & 0.281 \\
\hline \multirow{3}{*}{ G77 } & DB-FTi & $0.013(0.005)$ & $21.157 \quad(6.135)$ & - & - & - & $0.240 \quad(0.084)$ & $5.236 \quad(1.066)$ & 26.646 \\
\hline & CB-FTi & Traces & 7.242 (19.251) & - & - & - & $0.0783(0.016)$ & $1.145 \quad(3.190)$ & 8.465 \\
\hline & CB-FAc & $0.013(0.007)$ & $5.713 \quad(5.135)$ & - & - & - & $0.0156(0.005)$ & $2.082 \quad(1.440)$ & 7.824 \\
\hline \multirow{3}{*}{ G76 } & DB-FTi & - & $18.027(11.854)$ & - & - & - & $0.233 \quad(0.045)$ & $2.728 \quad(1.535)$ & 20.988 \\
\hline & CB-FTi & Traces & - & - & - & - & $0.0687(0.009)$ & - & 0.069 \\
\hline & CB-FAc & - & $7.203 \quad(6.800)$ & - & - & - & $0.0186(0.005)$ & $2.055 \quad(1.604)$ & 9.277 \\
\hline \multirow{3}{*}{$\mathrm{G} 75 \mathrm{~A}$} & DB-FTi & Traces & 7.529 (17.676) & - & - & - & $0.281 \quad(0.086)$ & $0.830 \quad(1.662)$ & 8.639 \\
\hline & CB-FTi & Traces & $0.711 \quad(1.401)$ & - & - & - & $0.0774(0.006)$ & - & 0.789 \\
\hline & CB-FAc & Traces & $1.447 \quad(0.910)$ & - & - & - & $0.0164(0.006)$ & $0.429 \quad(0.444)$ & 1.892 \\
\hline \multirow{3}{*}{ G75B } & DB-FTi & Traces & $6.785 \quad(5.165)$ & - & - & - & $0.268 \quad(0.065)$ & 1.107 (0.811) & 8.160 \\
\hline & CB-FTi & Traces & $3.457 \quad(7.288)$ & - & - & - & $0.0899(0.016)$ & $0.543 \quad(1.213)$ & 4.090 \\
\hline & CB-FAc & $0.013(0.006)$ & $10.703 \quad(9.489)$ & - & - & - & $0.0135(0.003)$ & 1.888 (1.436) & 12.617 \\
\hline \multirow{3}{*}{ G58 } & DB-FTi & $0.061(0.024)$ & $14.986 \quad(7.946)$ & - & - & - & $0.218 \quad(0.082)$ & $0.849 \quad(0.435)$ & 16.113 \\
\hline & CB-FTi & $0.040(0.021)$ & $13.923(18.474)$ & - & - & - & $0.0931(0.008)$ & $0.573 \quad(0.734)$ & 14.629 \\
\hline & CB-FAc & $0.012(0.014)$ & $7.874 \quad(3.318)$ & - & - & - & $0.0163(0.004)$ & $0.389 \quad(0.177)$ & 8.291 \\
\hline \multirow{3}{*}{ GP } & DB-FTi & $0.024(0.013)$ & $0.525 \quad(0.304)$ & Traces & $0.381(0.785)$ & - & $0.270 \quad(0.120)$ & $0.121 \quad(0.140)$ & 1.320 \\
\hline & CB-FTi & $0.482(0.413)$ & $10.634(27.244)$ & $0.039(0.041)$ & $0.447(0.596)$ & - & $0.0746(0.020)$ & $0.250 \quad(0.734)$ & 11.926 \\
\hline & CB-FAc & $0.015(0.008)$ & $14.241 \quad(9.381)$ & Traces & $0.251(0.329)$ & - & $0.0161(0.007)$ & $0.542 \quad(0.331)$ & 15.065 \\
\hline \multirow{3}{*}{ SL } & DB-FTi & $55.571(3.734)$ & - & - & $34.557(4.272)$ & $3.246(0.333)$ & $0.201 \quad(0.078)$ & $14.129(2.142)$ & 107.704 \\
\hline & CB-FTi & $14.014(6.485)$ & - & - & $18.871(5.463)$ & $1.310(0.379)$ & $0.1069(0.140)$ & $9.294 \quad(3.180)$ & 43.597 \\
\hline & CB-FAc & $9.254(0.796)$ & - & - & $13.971(1.746)$ & $0.923(0.087)$ & $0.0145(0.002)$ & $6.494 \quad(0.681)$ & 30.658 \\
\hline SAc & CB-FTi & - & - & - & - & - & $0.1500(0.019)$ & - & 0.150 \\
\hline
\end{tabular}


Ga, In, and Sn, were released at high levels, and only $\mathrm{Zn}$ was released, other than Ti, from the combinations with C98. The released levels of these elements were higher in the combinations with titanium than with acryl. Regarding gold alloys, the levels of $\mathrm{Cu}$ and $\mathrm{Zn}$ release were high. The standard deviation of the $\mathrm{Cu}$ release level was the largest, showing a large variation. The number of elements released from GP was the largest. The combination showing the highest level of release was SL/DB-FTi. Ti release showed a specific tendency depending on the combined fixture and fixing method, as described below. Fig. 2 shows the levels of $\mathrm{Ti}$ release in the $\mathrm{DB}-\mathrm{FTi}$ and $\mathrm{CB}-\mathrm{FTi}$ groups. In the DB-FTi group, the Ti release level was lower in the combinations with dental alloys than with the same metal, STi. When these measured values were subjected to the Kruskal Wallis test, significant differences were noted $(p<0.01)$. In the cement-fixed CB-FTi group, no significant difference was noted in the Ti release level among the combinations. The level of Ti release was markedly lower in the CB-FTi than in the DB-FTi group, and a markedly significant difference was detected on multiple comparison $(p<0.001)$.

Table 4 shows the levels of metal ions released from the combinations of the fixture FTi2 and superstructures (Ti2, C94, G76, GP, and SL) bound by direct fixation, DB-FTi2, and combinations of the fixture F64 and superstructures (S64, C94, G76, GP, SL, and STi) bound by direct fixation, DB-F64. Seven elements were released in the DB-FTi2 group and these were the same as those released from DB-FTi. V and a low level of Al were additionally detected in the DBF64 group. The total level of metal release was markedly higher in the combinations with SL, as noted in the DB-FTi, CB-FTi, and CB-FAc groups. Fig. 3 shows a comparison of the Ti release level between the groups using FTi2 and FTi for fixtures bound by direct fixation, DB-FTi2 and DB-FTi, respectively. Contrary to the DB-FTi group described above, the level of $\mathrm{Ti}$

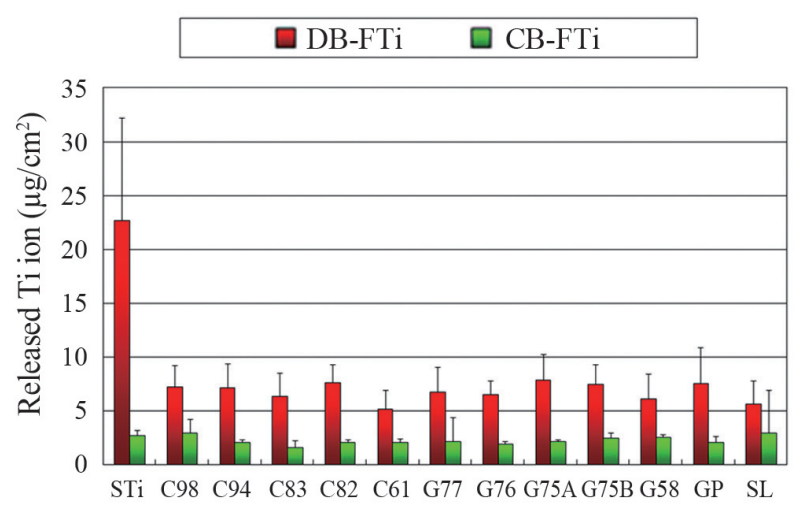

Fig. 2 Levels of Ti release from DB-FTi and CB-FTi.

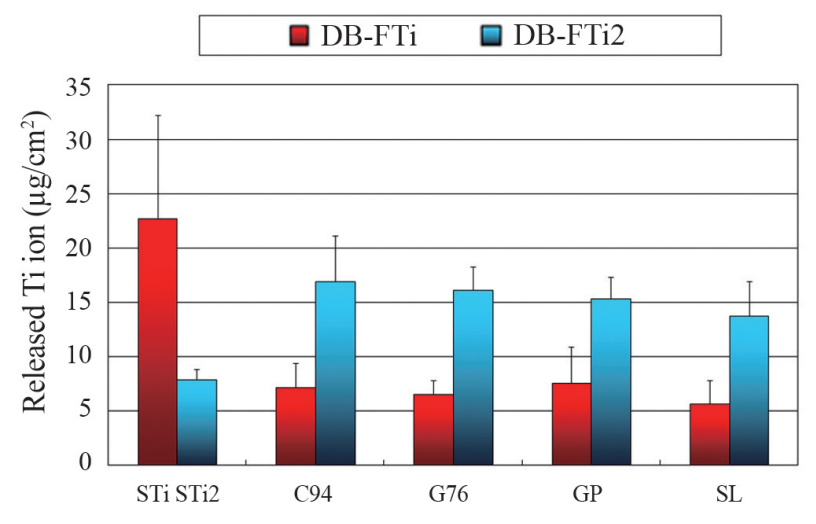

Fig. 3 Levels of Ti release from DB-FTi and DB-FTi2.

Table 4 Total levels of metal ion release from DB-FTi2 and DB-F64

\begin{tabular}{|c|c|c|c|c|c|c|c|c|c|c|c|}
\hline \multicolumn{2}{|c|}{ Sample } & \multicolumn{10}{|c|}{ Released ion concentratoin (ppm) } \\
\hline $\begin{array}{c}\text { Super- } \\
\text { structure }\end{array}$ & Group & $\mathrm{Ag}$ & $\mathrm{Al}$ & $\mathrm{Cu}$ & $\mathrm{Ga}$ & In & $\mathrm{Sn}$ & $\mathrm{Ti}$ & $\mathrm{V}$ & $\mathrm{Zn}$ & Total \\
\hline STi2 & \multirow{5}{*}{ DB-FTi2 } & - & - & - & - & - & - & $0.493(0.060)$ & - & - & 0.493 \\
\hline C94 & & - & - & - & $0.159(0.080)$ & $2.451(0.574)$ & $0.157(0.039)$ & $0.604(0.150)$ & - & - & 3.372 \\
\hline G76 & & - & - & $3.447(7.602)$ & - & - & - & $0.575(0.077)$ & - & $0.729(1.409)$ & 4.751 \\
\hline GP & & $0.019(0.008)$ & - & $1.148(1.761)$ & $0.024(0.011)$ & $0.064(0.079)$ & - & $0.547(0.072)$ & - & $0.166(0.204)$ & 1.967 \\
\hline SL & & 20.299 (15.015) & - & - & - & $13.253(9.993)$ & $1.154(0.873)$ & $0.489(0.113)$ & - & $6.078(4.892)$ & 41.273 \\
\hline S64 & \multirow{6}{*}{ DB-F64 } & - & Traces & - & - & - & & $0.649(0.162)$ & $0.031(0.007)$ & - & 0.681 \\
\hline C94 & & - & Traces & - & $0.325(0.250)$ & $2.319(0.982)$ & $0.117(0.052)$ & $0.319(0.078)$ & $0.016(0.004)$ & - & 3.096 \\
\hline G76 & & - & Traces & $0.885(0.860)$ & - & - & - & $0.326(0.021)$ & $0.017(0.001)$ & $0.224(0.282)$ & 1.451 \\
\hline GP & & $0.013 \quad(0.012)$ & Traces & $2.299(2.671)$ & Traces & $0.041(0.080)$ & - & $0.340(0.072)$ & $0.017(0.003)$ & $0.226(0.223)$ & 2.937 \\
\hline SL & & 56.800 (12.309) & Traces & - & - & $38.971(9.963)$ & $3.141(0.725)$ & $0.233(0.032)$ & $0.009(0.002)$ & $18.671(4.838)$ & 117.827 \\
\hline $\mathrm{STi}$ & & - & Traces & - & - & - & - & $1.158(0.963)$ & $0.037(0.031)$ & - & 1.195 \\
\hline
\end{tabular}




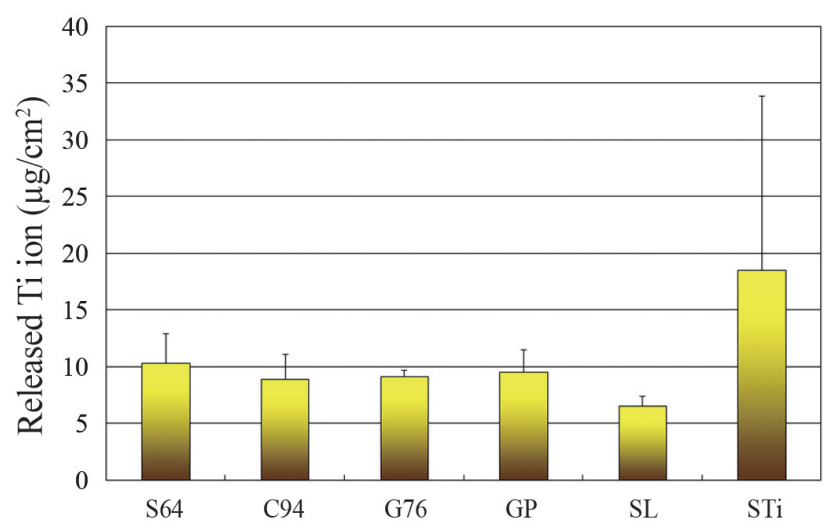

Fig. 4 Levels of Ti release from DB-F64.

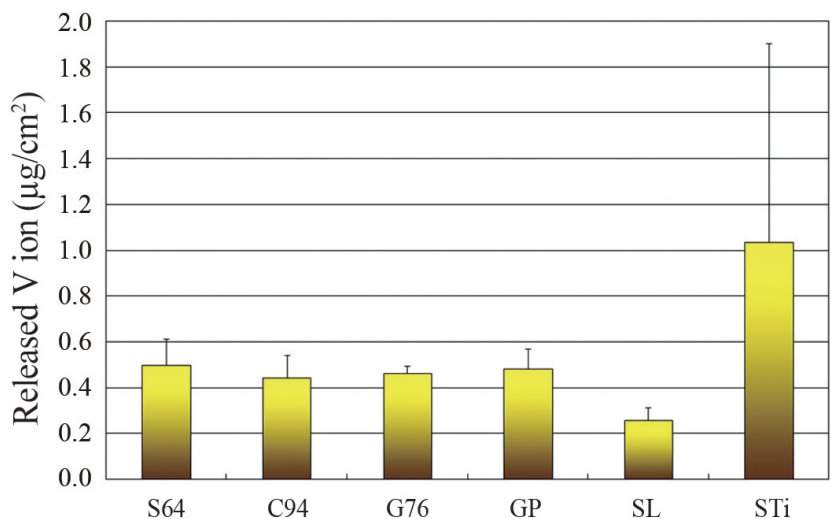

Fig. 5 Levels of V release from DB-F64.

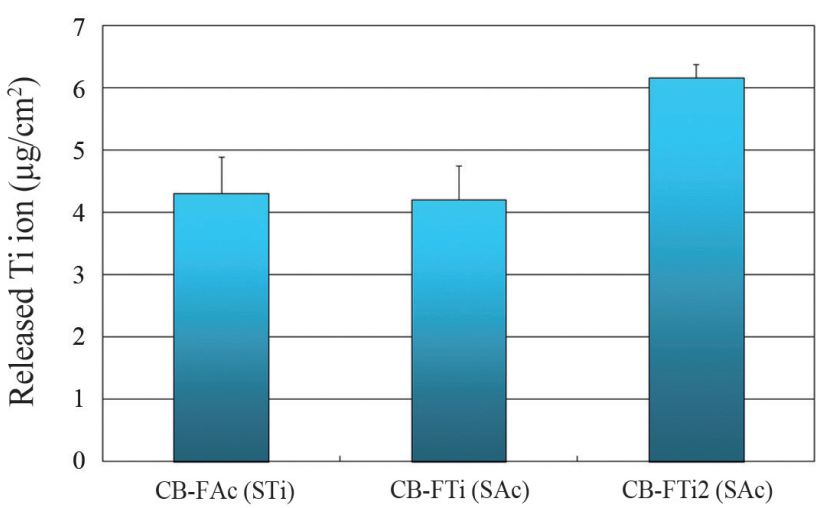

Fig. 6 Levels of Ti release from titanium materials and acryl bound by cement fixation.

CB-FAc (STi): Titanium superstructure (STi) and acrylic fixture (FAc) bound by cement fixation.

CB-FTi (SAc): Acrylic superstructure (SAc) and titanium fixture (FTi) bound by cement fixation. CB-FTi2 (SAc): Acrylic superstructure (SAc) and titanium fixture (FTi2) bound by cement fixation.

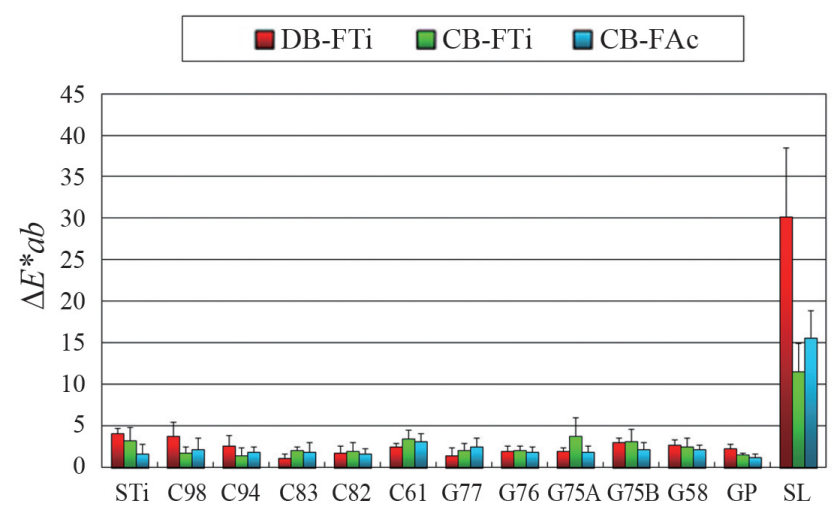

Fig. 7 Discolorations of superstructures after immersion in DB-FTi, CB-FTi, and CB-FAc.

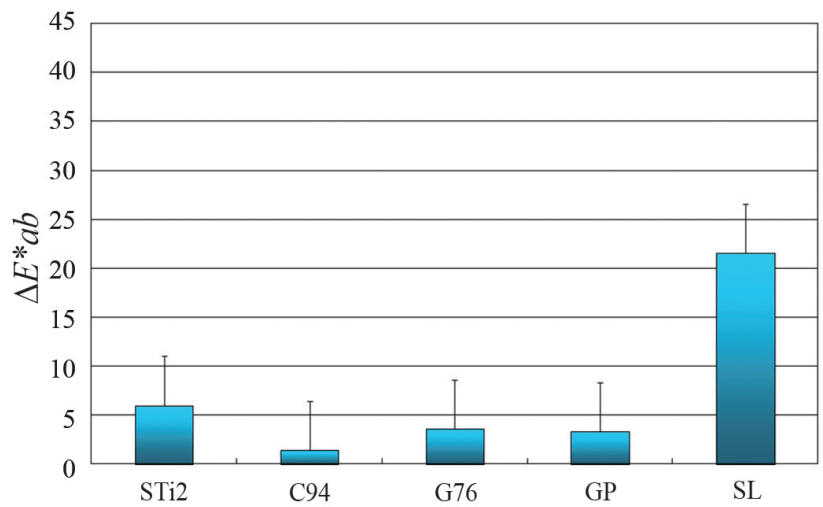

Fig. 8 Discolorations of superstructures after immersion in DB-FTi2.

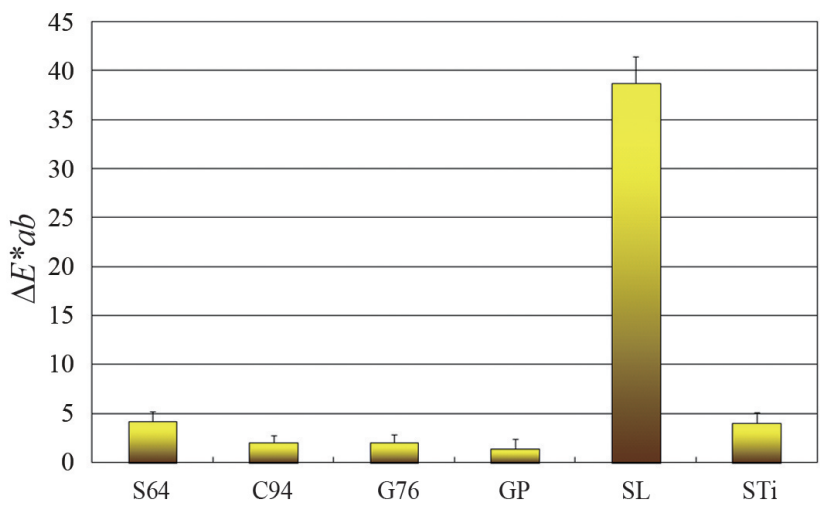

Fig. 9 Discolorations of superstructures after immersion in DB-F64. 

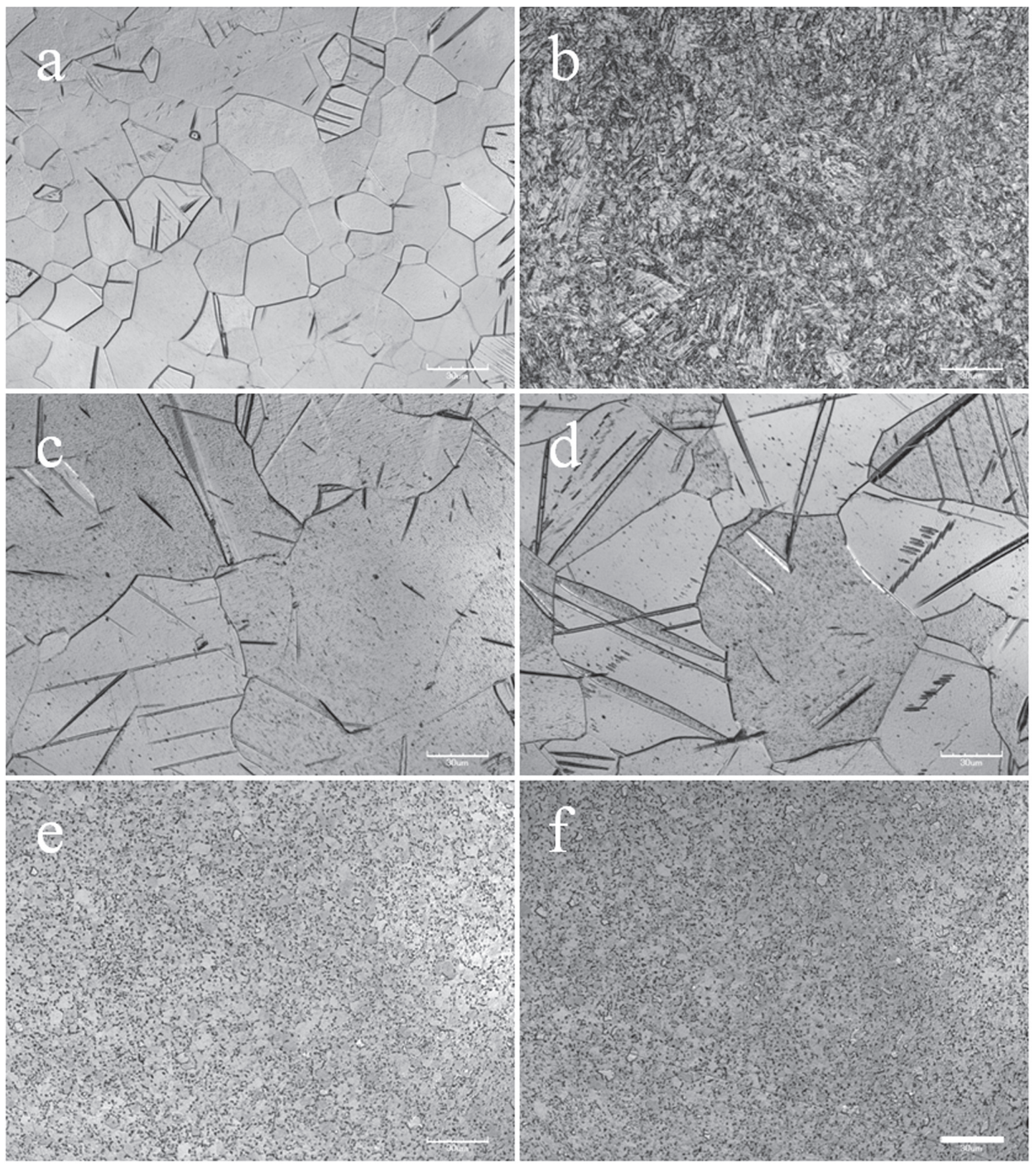

Fig. 10 Photographs of micro-structure of metals of titanium and titanium alloy used for experiments. a: STi, b: FTi, c: STi2, d: FTi2, e: S64, f: F64. Bar is $30 \mu \mathrm{m}$.

release was higher in the combination with precious metals than in that with the same metal, STi, in the DB-FTi2 group. On comparison between the two titanium-titanium combinations, the Ti level was lower in DB-FTi2 than in DB-FTi, and the difference was highly significant on two-way layout ANOVA $(p<0.001)$.

Fig. 4 shows the level of Ti release from DB-F64 in which the fixture F64 was directly bound. No significant difference was noted in the release level between the titanium alloy-titanium alloy and titanium alloy-dental alloy combinations. However, the level was higher in the combination with STi compared to those in the other conditions, and the difference was significant on the Kruskal Wallis test $(p<0.01)$. Fig. 5 shows the $\mathrm{V}$ release levels. The level of release showed a similar tendency to that of Ti: there were no marked 

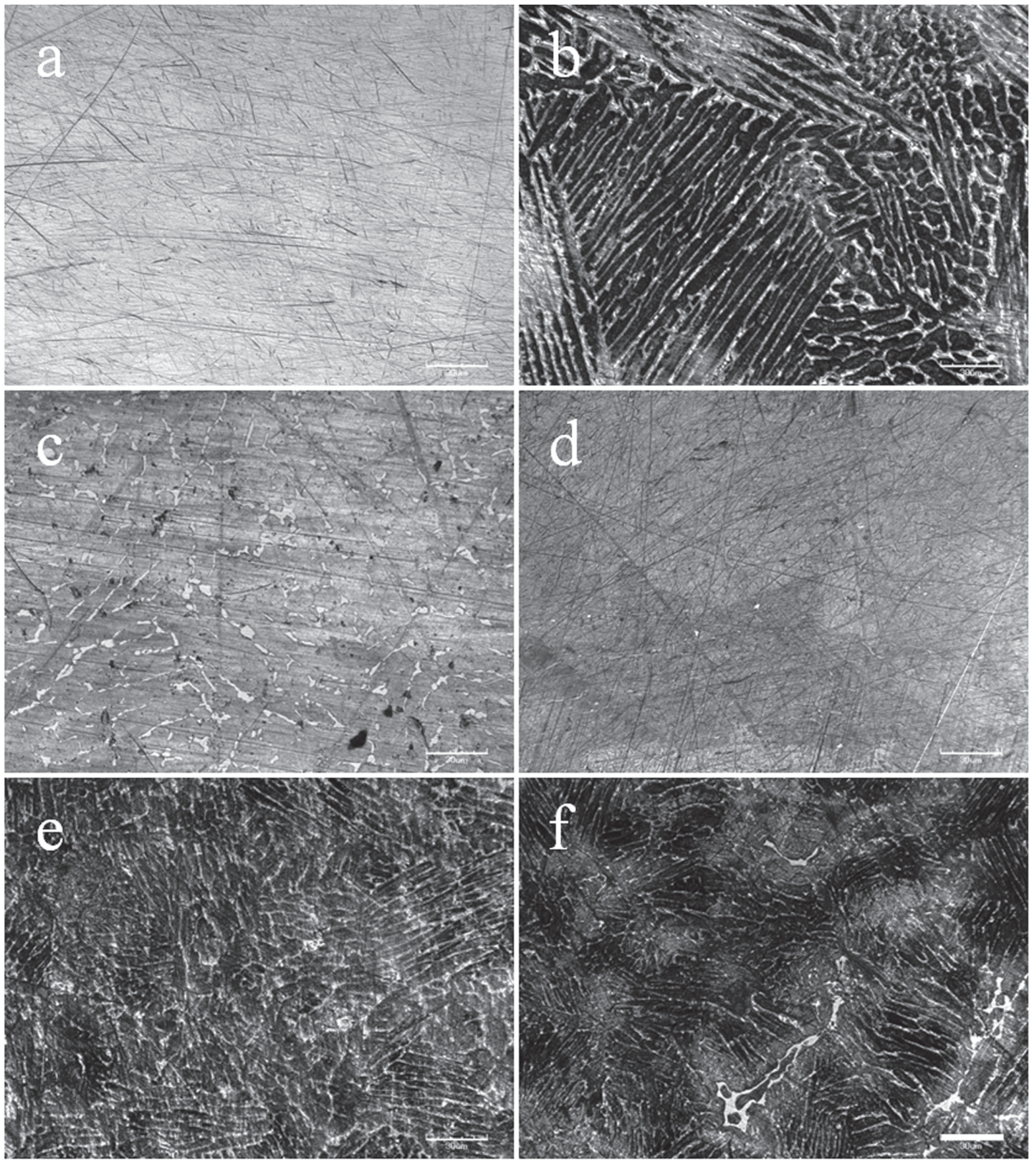

Fig. 11 Microscopic photographs of the occlusal surfaces of superstructures under all conditions using SL before and after immersion. a: SL (before immersion), b: DB-FTi, c: CB-FTi, d: CB-FAc, e: DB-FTi2, f: DB-F64. Bar is $30 \mu \mathrm{m}$.

differences between the titanium alloy-titanium alloy and titanium alloy-dental alloy combinations, but the level was higher in the combination with STi compared to those in the other conditions, and the difference was significant on the Kruskal Wallis test $(p<0.01)$.

Fig. 6 shows the Ti levels released from the STi/ acrylic fixture (FAc) bound by cement fixation and acrylic superstructures (SAc)/ FTi and FTi2 bound by cement fixation. On one-way layout ANOVA of these measured values, a markedly significant difference was noted between the titanium types $(p<0.001)$, and markedly significant differences were observed between FTi/STi and FTi2 on Tukey's multiple comparison $(p<0.001)$. 


\section{Measurement of discoloration after immersion}

Fig. 7 shows the discoloration of superstructures in the DB-FTi, CB-FTi, and CB-FAc groups, Fig. 8 shows those in the DB-FTi2 group, and Fig. 9 shows those in DB-F64. The largest change was noted in the combination with SL regardless of the condition, and a markedly significant difference was detected on the Kruskal-Wallis test $(p<0.001)$. The discoloration of the F64/SL combination bound by direct fixation was the most marked (38.71 \pm 2.73$)$, followed by FTi/SL bound by direct fixation $(30.20 \pm 8.29)$. The color difference was 6 or less in all other samples not combined with SL.

\section{Observation of micro-structure of metal}

Fig. 10 shows photographs of micro-structure of metals of titanium and titanium alloy (STi: a, FTi: b, STi2: c, FTi2: d, S64: e, F64: f). The grain size varied among the titanium types used in this experiment, although all were JIS type 2, and the size decreased in the order of STi2, FTi2>STi>FTi. The twin was observed in all the titanium samples. The grain size of titanium alloy was smaller than that of titanium.

\section{Observation of surfaces}

Fig. 11 shows microscopic photographs of the occlusal surfaces of SL superstructures which showed marked changes after immersion: a: before immersion, b, c, d, e, and f: DB-FTi, CB-FTi, CB-FAc, DB-FTi2, and DBF64 after immersion, respectively. The photographs also show differences in the surface change after immersion depending on the combination. Discoloration occurred in all samples, and findings suggesting corrosion were observed. Marked corrosion was noted in DB-FTi, DB-FTi2, and DB-F64 prepared by direct fixation with titanium and titanium alloy.

\section{DISCUSSION}

The total release level was the highest in combination with SL regardless of the condition (Tables 3 and 4), which may have been due to the low corrosion resistance of SL because the maximum current density of $\mathrm{SL}$ is the highest due to its passivation ${ }^{19)}$. The highest total release level was detected when SL alloy was bound with titanium and titanium alloy by direct fixation. As seen on the surface observation (Fig. 11), this release may have been due to galvanic corrosion. Dental alloys are considered to exhibit high-level corrosion resistance, but metal ion release in vitro and in vivo has been reported ${ }^{20-22)}$. It has also been reported that, in gold alloys with a basic composition of Au-Ag$\mathrm{Cu}$, corrosion occurred in Ag-rich regions followed by $\mathrm{Cu}$-rich regions ${ }^{23)}$. Ag-rich and $\mathrm{Cu}$-rich regions may be formed because $\mathrm{Ag}$ and $\mathrm{Cu}$ do not fuse, promoting local galvanic corrosion ${ }^{24)}$. Accordingly, the release level may have been higher in the combinations with all $\mathrm{Cu}$ containing gold alloys and GP than in those with PFM alloys containing no $\mathrm{Cu}$. From the PFM alloys, characteristic trace elements not contained in gold alloys, such as Ga, In, and Sn, were released. However, the total release level was as low as that from titaniumtitanium combinations under all conditions excluding the combination with Zn-containing C98, which may have been due to the fact that the corrosion potential (natural electrode potential) of PFM alloys is higher than those of other dental alloys ${ }^{19}$.

Differences in the $\mathrm{Ti}$ release level were small among the 3 types of titanium with different microstructure of titanium bound with acryl by cement fixation, although the differences were significant (Fig. 6). Reportedly, because the corrosion of the metal often progresses from the crystal grain boundary ${ }^{25)}$, corrosion resistance is different from the actual experiment results although it is thought to be inferior because the percentage of the crystal grain boundary of the metal with small crystal grains is greater. On the other hand, the corrosion resistance of titanium is not altered through material histories, such as welding, processing, and heating ${ }^{26)}$, which is consistent with our findings. However, the level of $\mathrm{Ti}$ release was markedly influenced by the micro-structure of titanium in the metal/metal combinations (Fig. 3). The level of Ti released from FTi2 with a coarse-grained size was more than 2 times higher in the combinations with dental alloys than with acryl bound by cement fixation (Figs. 3 and 6 ). In contrast, Ti release from FTi with a finegrained size increased in the combinations with dental alloys than with acryl bound by cement fixation, but to only about half of that released from FTi2 (Fig. 3). Furthermore, the highest Ti release level was detected in the combination of titanium with different microstructure of titanium (Tables 3 and 4), suggesting that a condition similar to galvanic couple corrosion was formed between the same metal with different microstructure of metal. Similarly, the release level from combinations with the titanium alloy fixture was significantly higher in the combination with titanium superstructure exhibiting electrochemical properties similar to those of titanium alloy ${ }^{19)}$ than with titanium alloy cut out from the same wire and dental alloys (Fig. 4). These findings may also have been due to the difference in the micro-structure of metal between titanium alloy and titanium.

Kitamura et al. ${ }^{18)}$ performed an electrochemical investigation, and observed that titanium/titanium and titanium alloy/titanium alloy combinations were superior to titanium/titanium alloy and titanium/Au$\mathrm{Ag}-\mathrm{Pd}$ alloy combinations in terms of corrosion resistance. In addition, Foti et al. ${ }^{27)}$ reported that $\mathrm{Ti}$ was detected in bone around titanium fixtures when dental alloys were used for superstructures, while no $\mathrm{Ti}$ was detected when titanium was used for superstructures in an animal experiment. On the other hand, Reclaru et al. ${ }^{13)}$ and Grosgogeat et al. ${ }^{28)}$ investigated galvanic corrosion, and found that the galvanic current was very low in titanium/precious metal combinations, having only a small influence on corrosion. The previously reported inconsistent data on $\mathrm{Ti}$ release described above ${ }^{13,18,27,28)}$ may have been associated with the micro-structure of titanium, and 
consideration of the micro-structure of metal of titanium and titanium alloys may be necessary to consider combinations of titanium and titanium alloys with other metals. This may also similarly apply to $\mathrm{V}$ release, which showed a similar tendency to that of the Ti release level (Fig. 5). Ti release at $0.0135-0.0216$ ppm was detected in the combinations with CB-FAc containing no Ti (Table 3). To confirm this finding, the cement alone was immersed in 1\% lactic acid and subjected to ICP analysis. Al, B, Ga, Fe, Mg, Si, Ti, and $\mathrm{Zn}$ were detected, suggesting that the Ti released was derived from the cement. Similarly, about 0.01-0.02 ppm of Ti released from cement-fixed CB-FTi may have been derived from cement.

Regarding the biological influences of released metals, the maximum Ag release during the 3-month immersion was 56.8 ppm from DB-F64 (SL) (Table 4). Inoue et $a l .^{29)}$ reported that $\mathrm{Ag}$ is unlikely to cause allergy because the positive $\mathrm{Ag}$ sensitization rate is the lowest, being only $0.1 \%$, in both healthy and morbid persons, suggesting that the risk is low. $\mathrm{Cu}$ is an essential trace element in humans, and the estimated average requirements are $0.6-0.7$ and $0.5-0.7 \mathrm{mg} /$ day for adult men and women, respectively, and the tolerable upper intake level is $10 \mathrm{mg} / \mathrm{day}^{30)}$. The maximum $\mathrm{Cu}$ release during 3-month immersion was $21.2 \mathrm{ppm}$ from DB-F64 (G77), suggesting that the risk is low. Regarding Ga, the 50\% lethal dose (LD50) of cytotoxicity for mouse fibroblasts has been reported to be $0.251 \mathrm{ppm}$ of $\mathrm{Ga}^{3+}\left(\mathrm{GaCl}_{3}: 3.60 \times 10^{-5} \mathrm{~mol} \mathrm{~L}^{-1}\right)^{31)}$. The maximum $\mathrm{Ga}$ release during the 3 -month immersion was 0.295 ppm from DB-F64 (C94), suggesting that the risk is also low. Regarding In, Inoue et al. ${ }^{29)}$ reported positive sensitization rates of 0.4 and $2.8 \%$ in healthy and morbid persons, respectively. The maximum In release during the 3 -month immersion was $39.0 \mathrm{ppm}$ from DB-F64 (SL), for which the risk of allergy cannot be neglected, although the positive sensitization rate in morbid persons is lower than those for other metals. Materials containing no In should be selected for persons with In allergy. Inoue et $a l^{29)}$ also reported that the positive $\mathrm{Sn}$ sensitization rates were 6.3 and $13.3 \%$ in healthy and morbid persons, respectively. The maximum Sn release during 3-month immersion was $56.8 \mathrm{ppm}$ from DB-FTi (SL), which may involve a risk of allergy even in healthy persons. $\mathrm{Zn}$ is also an essential trace element for humans, and gustatory disorder is reportedly a typical symptom of $\mathrm{Zn}$ deficiency. The estimated average requirement and tolerable upper intake level are 9-10 and 40-45 mg/day for adult men and 7-8 and 30-35 mg/day for adult women, respectively ${ }^{30)}$. The positive $\mathrm{Zn}$ sensitization rates were reported to be 1.7 and $7.3 \%$ in healthy and morbid persons, respectively ${ }^{29)}$. The maximum $\mathrm{Zn}$ release during the 3 -month immersion was $21.2 \mathrm{ppm}$ from DB-F64 (SL), suggesting that the risk may be low for healthy but high for morbid persons. Materials containing no $\mathrm{Zn}$ should be selected for those with $\mathrm{Zn}$ allergy. Titanium shows high-level corrosion resistance due to the passive surface capsule and biocompatibility, but Fujimoto ${ }^{32)}$ reported that the mouse fibroblast colony formation rate was $0 \%$ in the presence of 20 ppm of $\mathrm{Ti}^{4+}$ on a cytotoxicity test, showing its toxicity. The maximum $\mathrm{Ti}$ release during the 3-month immersion was $1.4 \mathrm{ppm}$ from DB-FTi (STi), and the colony formation rate may be $99-84 \%$ based on the findings reported by Fujimoto, suggesting that the toxicity is low. Roppongi et al. ${ }^{33)}$ implanted a test fragment consisting of pure titanium contacted with Co-Cr alloy in rabbits and found that Co release was promoted, suggesting that the combination of titanium with $\mathrm{Co}-\mathrm{Cr}$ alloy is inappropriate because the positive Co sensitization rate is high. Meachim et al. ${ }^{34)}$ reported that $\mathrm{Ti}$ and $\mathrm{Fe}$, which are unstable as ions, are likely to accumulate in the surrounding tissue. Moreover, titanium and titanium alloy allergies have recently been reported ${ }^{35,36)}$. On the other hand, the negativity of patients with titanium hypersensitivity on patch and intracutaneous tests with titanium salts has been reported, and the usefulness of in vitro lymphocyte stimulation and transformation tests have been investigated $^{37,38)}$. Okazaki et al. ${ }^{39)}$ reported that the stress region of titanium and its surroundings serve as an anode and cathode under frictional conditions, respectively, and promote corrosion compared to that under static conditions. Moreover, Kumazawa et al. ${ }^{40)}$ reported that titanium particles induced cytotoxicity. These reports suggest that the investigation of titanium particles which may be produced by friction is necessary in order to use titanium as a material for the occlusal surface. Although titanium and titanium alloys are considered to be superior in terms of corrosion resistance and biocompatibility, and criteria for use in implants have been established, corrosion and influences on biological tissue have been reported, as described above.

It was suggested that cement fixation is appropriate for the binding of superstructures with fixtures because it was less influential on the binding of different alloys and titanium materials with different micro-structure of metal with regard to the level of Ti release. Concerning metals for superstructures, PFM alloys may be suitable because the total metal ion release level was low. In titanium and titanium alloy implant systems composed of two or more pieces, it was thought that it was preferable that those microstructures of metal were similar. Furthermore, a small grain size of Ti may be favorable for fixtures because the levels of Ti released from combinations with dental alloys were low.

\section{CONCLUSION}

Superstructures prepared with titanium, titanium alloy, dental alloys, and acryl were bound with titanium or titanium alloy fixtures by cement or direct fixation, and these test samples were immersed in $1 \%$ lactic acid solution for 3 months. The released metal ion levels and discoloration of superstructures after immersion were measured, and titanium and titanium 
alloy tissues and the surfaces of the test samples before and after immersion were observed. The following conclusions were made:

1. The Ti release level was significantly lower in cement-fixed titanium/titanium and titanium/ dental alloy combinations than in those directly fixed.

2. The Ti release level from titanium/dental alloy combinations was influenced by the microstructure of titanium, and the level of release decreased when the titanium grain size was small.

3. In titanium/titanium combination, differences in the micro-structure of metal markedly influenced the release, and the level of release increased when the micro-structure of titanium was different.

4. Regarding the combination with titanium alloy, the $\mathrm{Ti}$ and $\mathrm{V}$ release levels were higher when titanium alloy was used in combination with titanium than with titanium alloy and dental alloy.

\section{ACKNOWLEDGMENTS}

I am grateful to Professor Michio Ito and Associate Professor Sakae Nagasawa, Department of Biomaterials, Matsumoto Dental University Graduate School, and Lecturer Takamitsu Yoshida and Assistant Professor Kaoru Tamura, Dental Science and Engineering, Matsumoto Dental University. I also greatly appreciate Hirohisa Yamamoto, Chairman of the Board of Directors, and Teruo Anraku, Managing Director, Yamamoto Previous Metal Co., Ltd., for giving me the opportunity to perform this study.

\section{REFERENCES}

1) Chee W, Felton DA, Johnson PF, Sullivan DY. Cemented versus screw-retained implant prostheses: which is better? Int J Oral Maxillofac Implants 1999; 14: 137-141.

2) Guichet DL, Caputo AA, Choi H, Sorensen JA. Passivity of fit and marginal opening in screw- or cement-retained implant fixed partial denture designs. Int J Oral Maxillofac Implants 2000; 15: 239-246.

3) Karl M, Rosch M, Graef F, Taylor TD, Heckmann SM. Static implant loading caused by as-cast metal and ceramicveneered superstructures. J Prosthet Dent 2005; 93: 324330.

4) Zarone F, Sorrentino R, Traini T, Lorio DD, Caputi S. Fracture resistance of implant-supported screw- versus cement-retained porcelain fused to metal single crowns: SEM fractographic analysis. Dent Mater 2007; 23: 296-301.

5) Karl M, Graef F, Taylor TD, Heckmann SM. In vitro effects of load cycling on metal-ceramic cement- and screw-retained implant restorations. J Prosthet Dent 2007; 97: 137-140.

6) Tamura K, Yoshida T, Yamazoe M, Mizoguch T, Niiro T, Kawase Y, Nagasawa S, Ito M. Hardness and metallographic structure of commercial titanium wires and implants. Proceedings of the 87th General Session \& Exhibition of the IADR; 2009 Apr 1-4; Miami, FLA, USA. Alexandria, VA: IADR; 2009. p. 114942.

7) Johansson BI, Lemons JE, Hao SQ. Corrosion of dental copper, nickel, and gold alloys in artificial saliva and saline solutions. Dent Mater 1989; 5: 324-328.

8) Japanese Industrial Standards Committee, Testing method for corrosion resistance of metallic biomaterials by anodic polarization measurement, JIS T 0302:2000, Tokyo: Japanese Standard Association; 2000. p. 1-18.

9) Koike M, Fujii H. The corrosion resistance of pure titanium in organic acids. Biomaterials 2001; 22: 2931-2936.

10) Huang HH, Chiu YH, Lee TH, Wu SC, Yang HW, Su KH, $\mathrm{Hsu}$ CC. Ion release from NiTi orthodontic wires in artificial saliva with various acidities. Biomaterials 2003; 24: 35853592.

11) Yoneyama T, Doi H, Hamanaka H. Released metallic ion from Ti, Ti-6Al-4V alloy and Ni-Ti alloy. Seitai Zairyo 1993; 11: 71-78.

12) Okazaki Y, Gotoh E, Manabe T, Kobayashi K. Comparison of metal concentrations in rat tibia tissues with various metallic implants. Biomaterials 2004; 25: 5913-5920.

13) Reclaru L, Meyer JM. Study of corrosion between a titanium implant and dental alloys. J Dent 1994; 22: 159-168.

14) Tanaka K. Corrosion mechanism of coupled dental alloys. Tohoku Univ Dent J 1996; 14: 119-138.

15) Nakada H, Okazaki Y, Saeki H, Kobayashi K, Tateishi T. Galvanic corrosion of various dental alloys and centrifugally cast new titanium alloy couples. Seitai Zairyo 1998; 16: 243253.

16) Venugopalan R, Lucas LC. Evaluation of restorative and implant alloys galvanically coupled to titanium. Dent Mater 1998; 14: 165-172.

17) Cortada M, Giner LL, Costa S, Gil FJ, Rodriguez D, Planell JA. Galvanic corrosion behavior of titanium implants coupled to dental alloys. J Mater Sci Mater Med 2000; 11: 287-293.

18) Kitamura T, Yoshinari M, Oda Y. Electrochemical behavior of coupled dental implant alloys. Shikwa Gakuho 2002; 102: 665-675

19) Sakaihara I, Yamazoe M, Anraku T, Yoshida T, Tamura K, Nagasawa S, Ito M. Corrosion resistance of dental precious metal alloys in pseudo-oral environment. Matsumoto Shigaku 2007; 33: 200-209.

20) Gettleman L, Cocks FH, Darmiento LA, Levine PA, Wright $\mathrm{S}$, Nathanson D. Measurement of in vivo corrosion rates in baboons, and correlation with in vitro tests. J Dent Res 1980; 59: 689-707.

21) Marek M. Corrosion in a biological environment. Proceedings of the International workshop on Biocompatibility, toxicity and hypersensitivity to alloy system used in dentistry; 1985 Jun 23-28; Ann Arbor, MI, USA. Michigan: University of Michigan School of Dentistry; 1986. p. 103-122.

22) Lucas LC, Lemons JE. Biodegradation of restorative metallic systems. Adv Dent Res 1992; 6: 32-37.

23) Laub LW, Stanford JW. Tarnish and corrosion behavior of dental gold alloys. Gold Bull 1981; 14: 13-18

24) The Japan Institute of Metals. Kinzoku data book. 4th ed. Tokyo: Maruzen Co; 2004. p. 519.

25) Suzuki K, Umemoto K, Okazaki M, Nakajima H, Nishiyama, N. Standard dental materials science. 4th ed. Tokyo: Gakkensyoin; 2009. p. 17.

26) Kusamichi H. Application of titanium metal. 1st ed. Tokyo: The Nikkan Kogyo Shinbun; 1987. p. 218-223.

27) Foti B, Tavitian P, Tosello A, Bonfil JJ, Franquin JC. Polymetallism and osseointegration in oral implantology: pilot study on primate. J Oral Rehabil 1999; 26: 495-502.

28) Grosgogeat B, Reclaru L, Lissac M, Dalard F. Measurement and evaluation of galvanic corrosion between titanium/ Ti6Al4V implants and dental alloys by electrochemical techniques and auger spectrometry. Biomaterials 1999; 20: 933-941. 
29) Inoue M. Epidemiological survey of metal allergy and its relationship with oral metal restorations. Grant-in-Aid for Co-operative Research (A). Research Project Number : 01304047 Final Research Report, 1992.

30) Dietary reference intakes for Japanese (2010), Japan: Ministry of health, Labor and welfare; 2009. p. 218-275.

31) Yamamoto A, Honda R, Sumita M. Cytotoxicity evaluation of 43 metal salts using murine fibroblasts and osteoblasttic cells. J Biomed Mater Res 1998; 39: 331-340.

32) Fujimoto K. An Experimental Study of Ti-Ni binary alloy as the material for implant. J Jpn Soc Oral Implant 1986; 7: 25-55.

33) Roppongi S, Higo Y. Experimental study on corrosion behavior in total Joint prosthesis employing different metals. Seitai Zairyo 1995; 13: 5-13.

34) Meachim G, Williams DF. Changes in nonosseous tissue adjacent to titanium implants. J Biomed Mater Res 1973; 7: $555-572$.

35) Schweitzer A. First report of a titanium allergy. Dermatosen 1997; 45: 190

36) Nakano T, Ko N, Ko R, Shimazu T, Egusa H, Yamada S, Yatani H. Titanium allergy of dental implant. : A Case
Report. Proceedings of the 37th Academic Conference of the Japanese Society of Oral Implantology; 2007 Sep 14-16; Kumamoto, Japan. Tokyo: Japanese Society of Oral Implantology; 2007. p. 339.

37) Tamai K, Mitsumori M, Fujishiro S, Kokubo M, Ooya N, Nagata Y, Sasai K, Hiraoka M, Inamoto T. A Case of allergic reaction to surgical metal clips inserted for postoperative boost irradiation in a patient undergoing breast-conserving therapy. Breast Cancer 2001; 8: 90-92.

38) Takada A, Ujigawa K, Okazaki Y, Ozawa Y, Morimoto M, Tonogi M, Yamane G. A case suspected hypersensitivity to titanium lymphocyte transformation test for hypersensitivity to titanium. Proceedings of the 37th Academic Conference of the Japanese Society of Oral Implantology; 2007 Sep 14-16; Kumamoto, Japan. Tokyo: Japanese Society of Oral Implantology; 2007. p. 339.

39) Okazaki Y, Kyo K, Ito Y, Tateishi T. Effect of friction on the corrosion resistance for implant alloys in physiological saline solution. J Japan Inst Metals 1997; 61: 1122-1131.

40) Kumazawa R, Watari F, Takashi N, Tanimura Y, Uo M, Totsuka Y. Effects of Ti ions and particles on neutrophil function and morphology. Biomaterials 2002; 23: 3757-3764. 